\title{
"The tropical forest and fire emissions experiment: laboratory fire measurements and synthesis of campaign data" published in Atmos. Chem. Phys., 8, 3509-3527, 2008
}

\author{
R. J. Yokelson ${ }^{1}$, T. J. Christian ${ }^{1}$, T. G. Karl ${ }^{2}$, and A. Guenther ${ }^{2}$ \\ ${ }^{1}$ University of Montana, Department of Chemistry, Missoula, MT, USA \\ ${ }^{2}$ National Center for Atmospheric Research, Boulder, CO, USA
}

Erroneously Fig. 2 in the published article includes panel (b) twice. Below the correct figure with panel (a) and (b) is shown.
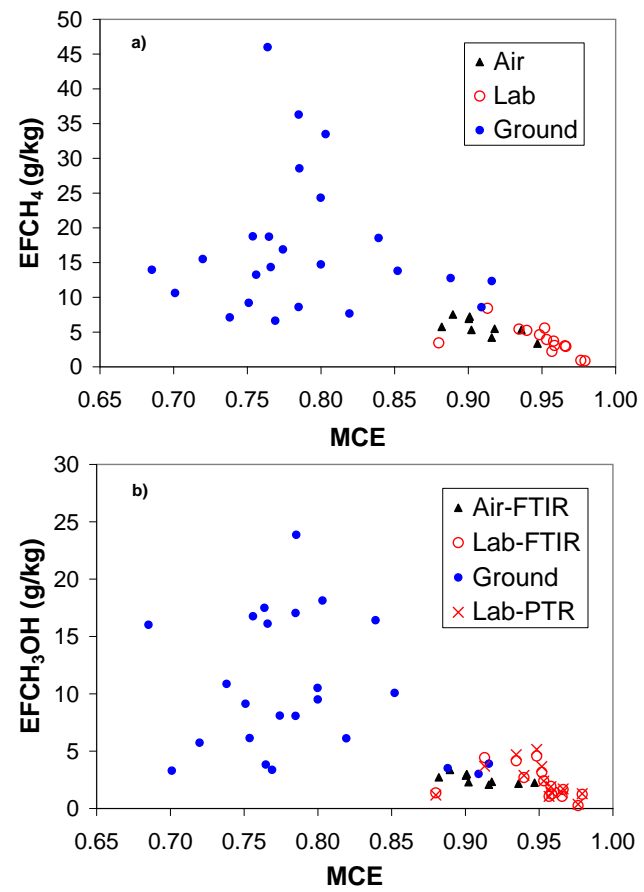

Fig. 2. Presentation of all the emission factors measured during TROFFEE from ground-based, airborne, and laboratory platforms for $\mathrm{CH}_{4}$ (a) and $\mathrm{CH}_{3} \mathrm{OH}$ (b). Despite differences in fuels between the experiments, these compounds show a consistent trend of increasing emissions with decreasing MCE indicating fuelindependent production largely by smoldering combustion. There is also a large range in the EF observed (factor of $\sim 20$ ).

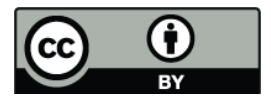

Correspondence to: R. J. Yokelson

(bob.yokelson@umontana.edu)

Published by Copernicus Publications on behalf of the European Geosciences Union. 